\title{
DE BESCHRIJVING DER VERZAMELING MALEISCHE HANDSCHRIFTEN TE BERLIJN VAN WIJLEN C. SNOUCK HURGRONJE. ${ }^{1}$ )
}

\author{
DOOR
}

Dr. PH. S. VAN RONKEL.

In zijn opstel Nog iets over de Salasila van Koetai, verschenen in onze Bijdragen, $5^{\circ}$ volgr. deel III, bl. 109-120 - in deel C. bl. 405-416 - mocht ik daarvan met eenige uitvoerigheid melding maken, waardoor verdere aanhaling of verwijzing onnoodig wordt schreef Dr. C. Snouck Hurgronje: „Nu schijnt de Salasila eene zeer schaarsche verbreiding te hebben gevonden; het valt zelfs te betwijfelen of er in Oost-Indië meer dan een enkel exemplaar, dat van den sultan namelijk, voorhanden is. Het eenige afschrift dat naar Europa is gekomen, berust sedert eenige jaren" (het stuk is van 1888)" op de Königliche Hofbibliothek te Berlijn, waar het mij in Maart dezes jaars gedurende een kort verblijf aldaar, toevallig in handen kwam. In den afgeloopen zomer eenige weken in genoemde boekerij werkende, o.a. ter voorbereiding van een wetenschappelijken catalogus der Maleische handschriften, had ik gelegenheid dien tekst met het afschrift van den heer Tromp te collationneeren".

Eenige regels verder zegt de schrijver: „Het is $\mathrm{n}^{\circ} 2$ van de verzameling, die aan Dr. Schoemann heeft toebehoord, en na diens dood aan de Hofbibliothek is verkocht".

Die collectie komt wederom ter sprake, in 1893, in deel II van het onovertroffen werk $D e$ Atjèhers, waarin telkens verwijzingen naar nummers uit de verzameling voorkomen, die teksten bevatten van denzelfden inhoud als de Maleische versies der behandelde Atjèhsche litteratuurproducten.

Tot uitgeven van zijnen catalogus is de auteur nooit gekomen, en

1) Uitwerking van eene mededeeling op het $10^{\circ}$ congres van het „Oostersci Genootschap in Nederland", op 17 April 1941.

D1. 101. 
wel tengevolge van meeningsverschillen met de toenmalige Directie der Bibliotheek, in zake vorm en wijze der publicatie. De vraag: wie was Dr. Schoeman, is dank zij voorlichting van den heer R. A. Kern, gemakkelijk te beantwoorden. Hij was Hauslehrer bij de kinderen van den Gouverneur-Generaal Rochussen (1845-1851), reisde veel in Indië, verzamelde veel, en liet vele handschriften in onderscheidene talen copieeren, werd na zijn terugkeer in Europa bibliothecaris te Trier, en uit zijne nalatenschap is in 1879 de verzameling door de bovengenoemde Instelling te Berlijn aangekocht. De Maleische handschriften hebben de nummering $\mathrm{V}$, en de volgnummers in $\mathrm{zg}$ Arabische cijfers; de rubrieken I-IV bestaan waarschijnlijk uit Javaansche, Soendasche en andere, de rubrieken VI en VII uit Boegineesche en Makassaarsche, welker inventaris, naar de heer Kern nog mededeelde, kort en onbevredigend is.

Prof. Dr. B. J. O. Schrieke, die te Berlijn de manuscripten gezien heeft, deelde mij enkele bijzonderheden aangaande de niet-Maleische schrifturen mede, o.a. de aanwezigheid aldaar van eene kleine verzameling in de $5^{\circ}$ decade der vorige eeuw in eene kluizenarij op den Merbaboe in beslag genomen Javaansche geschriften, en dat wel naar aanleiding van eene politiek-godsdienstige beweging. Daaronder bevond zich een zeer fraai met oud-Javaansch schrift (met inkt) beschreven lontar-manuscript, dat op naam van Patañjali stond; van die beweging is voorzoover na te gaan uit de literatuur niets bekend.

Vele jaren heeft het geduurd eer de collectie weder ter sprake kwam n.l. door het verschijnen van eene inventariseering er van, in 1926, bewerkt door Hans Overbeck, in Part II van Vol. IV van het Journal of the Malayan Branch of the Royal Asiatic Society, bl. 233-259. Daar dit stuk in een bekend tijdschrift verschenen is, kunnen wij volstaan met een korte aanhaling er uit. De schrijver, die veel over Maleische verhalen geschreven, vrij wat uit het Maleisch in het Engelsch en Duitsch vertaald, en een overzicht der Maleische litteratuur gepubliceerd heeft, bericht, dat hij in 1925 tijdens een Europeesch verlof, op verzoek van Dr. R. O. Winstedt, een onderzoek instelde naar de aanwezigheid van Maleische handschriften in openbare boekerijen in Duitschland, en in verschillende plaatsen manuscripten aantrof, die hem naar zijn verblijfplaats, Bremen, werden toegezonden. Hij had zeer weinig tijd, en geen der catalogi van de groote collecties handschriften ter beschikking, voelde zich dus niet voorbereid voor de taak; de beknoptheid zijner beschrijving mag hem dus niet euvel geduid worden. Twee en twintig bladzijden 
wijdt hij aan de Preuszische Staatsbibliothek te Berlijn (nl. bl. 235251 Collectie Schoemann, en zes „Other Manuscripts”), en drie aan de Sachsische Landesbibliothek te Dresden, de Bayerische Staatsbibliothek te München, en de Stadtbibliothek te Hamburg te samen.

Van de Collectie-Schoemann veronderstelt hij terecht, dat vele handschriften ervan ,are apparently copies of well known works made to order, probably for a European collector, as they seem to be very little used, and to judge from the handwriting are written by a few different scribes”. Minder juist is zijn gissing: „possibly they are copied from MSS. in the Batavian library".

Dadelijk treft ons het feit dat het gewone formaat folio is, en het papier Europeesch, het officieele genre dus, waaruit wij opmaken, dat de Hauslehrer, profiteerende van zijne positie ten paleize, allerlei teksten heeft laten copieeren, èn te Buitenzorg èn in residentiehoofdplaatsen waar het „Hollandsche papier” voor van hoogerhand herkomstige opdrachten beschikbaar was. Geheel in overeenstemming hiermede is dat vele HSS. in de jaren 1845-1851 vervaardigd zijn, gelijk uit verscheidene door Overbeck vermelde dateeringen blijkt.

Ons interesseert zijne mededeeling: Apparently Prof. Dr. C. Snouck Hurgronje has examined some of the MSS. of the Schoemann-catalogue (sic, lees: collection?), and the notes he left in the books were of great assistance to me".

Zooals gezegd zijn de beschrijvingen uiterst kort, met uitzondering van enkele, waar de schrijver zeer uitvoerig is, zooals bij de Hikajat Radja Singasayah, en de Risālat Hoek̄̄em Kanoen, welker indeeling in 44 paragraphen hij met al de titels weergeeft. Van de Schoemann-Verzameling behandelt hij 44, van de „Other MSS.” 4, en dan een aantal specimina herkomstig van de Indische Instelling te Delft. (De gemeenteraad dier stad heeft destijds de boekerij en vele ethnographica der Instelling naar Berlijn verkocht).

Het verlangen naar kennismaking met den origineelen catalogusSnouck Hurgronje bleef bestaan, en door bijzondere omstandigheden is de wel begrijpelijke wensch om die beschrijving te leeren kennen in vervulling gegaan. Het is velen bekend dat de groote oriëntalist al zijne boeken en manuscripten heeft vermaakt aan de Leidsche Universiteitsbibliotheek; onder de eerste rubriek noem ik slechts: belangrijke Arabische en voornamelijk buiten Indië gedrukte Maleische werken, zooals bij niemand waar ook aan te treffen waren, onder de tweede: een groot aantal Maleische, Soendasche en Atjehsche HSS., de laatste feitelijk de geheele Atjehsche litteratuur vertegenwoor- 
digend. Onder de HSS. bevinden zich eenige bescheiden, documenten e.d., en ook: de volledige beschrijving der Maleische MSS. te Berlijn, de collectie-Schoemann. Over dit belangrijke stuk moge ik thans eenige mededeelingen doen. Het bestaat uit eene Inleiding van VI bl. en den eigenlijken catalogus van 268 pagina's.

In de „Vorrede” wordt rekenschap gegeven vn de indeeling in rubrieken, den tijd der vervaardiging (bijna alle uit de $4^{\circ}$ decade der vorige eeuw, zie boven), en het systeem der catalogiseering. Zijne „Methode der Beschreibung wird sich hoffentlich selbst empfehlen”!

Titels alleen voldoen niet, dus de inhoud moest opgegeven worden; de eigenaardigheden van de redactie, schrift en spelling moeten worden aangeduid.

De weinige beschrijvingen van collecties-Maleische HSS. [Londen, Leiden (gebrekkig) en Batavia (ontoereikend)] worden genoemd, en telkens wanneer te pas komt, zal daarnaar worden verwezen. De behartigenswaardige slotpassus is: ,Schliesslich bemerke ich, in Anbetracht der weithin herrschenden Sitte, mallaiische Texte nach eignem Geschmack ohne kritische Grundsätze zu „verbessern” dass ich die von mir citierten Stellen möglichst genau nach den HSS. wiedergegeben habe, nur hier und da aus besonderen Gründen die bessere Lesart hinzufügend. Auf die Charakterisierung der HSS. kommt es ja an, und die zahllosen Schreibfehler kann jeder Sachverständige unschwer selbst verbessern".

De datum is: Leiden, Februar 1889.

Wanneer men het keurig geschrevene werk doorbladert, staat men verbijsterd tegenover het feit, dat dit ginds in enkele weken is voorbereid. Niet alleen worden groote citaten van begin en slot der HSS. gegeven, maar waar het mogelijk was vergelijkingen met tekstuitgaven of te Leiden aanwezige of ook Londensche MSS. gemaakt. Eindelijk wordt de schriftsoort medegedeeld - ook de maten en het aantal regels worden vermeld - en dat wel zeer nauwkeurig; of de G met een punt er onder of er boven, de $\mathrm{Ng}$ met drie punten of wel een boogje en één punt, of de $\mathrm{P}$ met één of drie punten wordt geschreven, dat alles wordt aangegeven. Nemen wij als specimen $\mathrm{n}^{\circ} 1$, de Hikajat Rawana, d.i. de Maleische versie der Rama-geschiedenis. De inhoudsopgave beslaat niet minder dan 12 bladzijden; telkens worden vergelijkingen met de uitgave van Roorda van Eijsinga gemaakt, zoowel over den inhoud als over den vorm der woorden. Bij de vermelding van de bekende figuur Nénék Kebajan wordt in eene noot verwezen naar andere teksten waarin deze ook voorkomt, zooals de Hikajat 
Indranata, de Hik. Indrapoetra, de Hik. Radja Rōm, de Hik. Si Miskīn (in Juynboll's catalogus wordt van eerstgenoemd feit geen gewag gemaakt, wel van de andere). Zoo iets kan dienen als een criterium voor de volkomene lectuur, die de beschrijver aan elk HS. gewijd heeft. Aan het tweede exemplaar der Rama-bewerking, Hikajat Seri Rama getiteld, zoude eene beknopte beschrijving ten deel kunnen vallen, maar eene uitvoerige, critisch-vergelijkende, descriptie van $4 \mathrm{bl}$. wordt er aan besteed, eindigend met eene caracteriseering van het schrift. Dan volgt een dubbelnummer: A de Hikajat Boma oder Samba, B de Hikajat Kerasana, waaraan 7 bl. besteed zijn. Typeerend is de aanhef: Dünnes holland. Papier, 140 beschriebene Seiten (70 gezählte Blätter), $291 / 2$ x 18 c.m., 19 Z., die zwei ersten Sein enhaben bloss 8 in einem schwarz und roth ornamentierten Rahmen gefasste Zeilen. Die HS., welche die Spuren der häufigen Benutzung von Eingeborenen zeigt, enthält zwei verschiedene zum gleichen Kreise gehörende Erzählungen”.

Daarna worden enkele zgn. „Lückenbüsser”, en de dateering vermeld, en de eigenaardigheden van het schrift als volgt beschreven: „Die Schrift ist deutlich, die Schreibung äusserst nachlässig und sonderbar, wie man aus den oben gegebenen Ausführungen ersieht. Abgesehen von der durchgängig regellosen Orthographie der Eigennamen kommen häufig Schreibungen vor wie..... Auch hat der Abschreiber manchmal ganze Stücke ausgelassen".

Op deze ,erschöpfend” complete wijze gaat het verder, met wajang-verhalen, den roman van Si Miskīn alias Mara Karma, het verhaal van Singasaja (in twee exemplaren), de Hikajat Indra Bangsawan, Randja Rōm of Indra Nata, en verscheidene andere. $\mathrm{Nu}$ en dan treffen ons merkwaardige opmerkingen, b.v. deze (naar aanleiding van de overeenkomst van het HS. Indra Poetra met twee Leidsche codices' „Man könnte meinen, sie wären von verschiedenen Leuten angefertigte Uebersetzungen eines Originals, welche denn noch die Modifikationen erlitten hätten, die malaiische Abschreiber ohne Scheu in die von ihnen behandelten Texte einzutragen pflegen ..... Einer wissenschaftlichen Herausgabe müsste ein gutes Ex. zu Grunde gelegt werden, und in ausführlichen Bemerkungen wären die Abweichungen der anderen anzuführen; jede andere Methode ergäbe eine Mischung nach europaischem Geschmack, wie ssie in den Publikationen malaiischer Texte schon allzu oft auftritt". Op deze wijze gaat het voort met de beschrijving van de HSS. die verhalen bevatten, tot de vermelding van de geschiedenis var 
Alexander den Grote de „Hikajat Iskandar Doù '1 Qarnain”. (bl. 110). De inhoudsopgave beslaat niet minder dan 18 bladzijden. Ze overtreft in omvang die der Leidsche en Bataviasche HSS. catalogi belangrijk, terwijl hare compositie voorbeeldig is te noemen; bovendien wordt eene tekstvergelijking met de beide Leidsche codices gegeven, en worden deze onderling vergeleken.

Voorzichtig voegt de beschrijver er aan toe: Ueber den Weg, welchen der Roman von Persien nach Ostindien genommen hat, habe ich Näheres nicht ermitteln können”. Ook bij de volgende nummers critische vergelijkingen met Leidsche HSS., en bij twee exemplaren van één' tekst te Berlijn collationneering dier specimina, benevens enkele comparaties van bijzondere scènes met andere, ook Atjèhsche, versies! Dat in den gang der eentonige verhalen ook het goede wordt opgemerkt en gewaardeerd, blijkt uit eene noot (bl. 138) als deze: „Im Laufe der Geschichte..... sind manche hübsche kleinere Erzählungen angebracht, in ziemlich breitem, aber sorgfältigem und hier und da elegantem Stil".

Over de uitvoerigheid der inhoudsopgave van de 15 verhalen eener zgn. Boenga Rampai (geschr. te Bogor in 1848!) behoeven wij niets meer te zeggen; dit was het laatste nummer der prosa-geschriften; dan volgen gedichten, voornamelijk pantoens, bij welker beschrijving de auteur, die nooit in Indië geweest was, blijk geeft eigenaardigheden van het Bataviasch dialect te kennen. Dat een gedicht over Mekka en Medina den schrijver nader aan het harte moet gelegen hebben dan pantoen-achtige rijmelarijen, spreekt vanzelf, al worden deze specimina niet minder degelijk behandeld dan gene; ons interesseert zijne appreciatie: „Im Ganzen ist die Darstellung richtig, obgleich nicht ohne Uebertreibung; diese geht ins Lächerliche, sobald der Dichter Zahlen angiebt...." Het weinig verhevene ontgaat hem niet, het woord „Dichter" voorziet hij van de bijvoeging "sit venia verbo", en de gewone liedjes noemt hij ,eben so wenig poetisch wie die meisten „Scha'ir's” denn der Reim beeinträchtigt in denselben manchmal die Klarheit des Ausdrucks, ohne den ästhetischen Werth im Geringsten zu erhöhen".

We komen nu tot de afdeeling: Muhammedanische Dogmatik, Gesetzkunde, Mystik und erbauliche Legenden. Ook hier, op dit den auteur zoo bij uitstek bekende terrein, dezelfde volledigheid en acribie als bij de andere capita! 't Z Zijn alle welbekende werken, wederom op gouvernementspapier, en voor zoo ver gedateerd, uit de bekende decade. Dat geschriften als de „Laatste Vermaning der Pro- 
feets aan zijne gemeente" den beschrijver nog meer stof tot zakelijke en critische vergelijking met verwante schrifturen boden, ligt in de rede. Na vijftien bladzijden (bl. 222) begint de afdeeling „Geschichte Ostindischer Dynastien"; eerst de kroniek van Bandjarmasin en Kotaringin, waarbij den soi-disant vertaler F. S. A. de Clercq verdiende afkeuring ten deel valt (,weder eine ,,genauere Uebersetzung” sondern eine..... unvollständige und manchmal dazu fehlerhafte Wiedergabe des Inhalts").

Dan de befaamde kroniek van Koetai, waaraan 7 bl. gewijd worden, een gedeelte, dat ons om bekende, boven aangegeven, redenen bijzonder interesseert. Hier herkennen wij den „referent”, waar hij zijne ,eingehende" behandeling aanvangt met de woorden: "Es wäre eine Lohnende Arbeit, die ganze Chronik zu bearbeiten und mit Erläuterungen zu versehen, die an Ort und Stelle einzuziehen, und dazu wäre unsere .... März 1849 angefertigte Kopie eien sehr werthvolles Hülfsmittel". Hoe goed stemmen deze woorden overeen met die in de geciteerde verhandeling in de Bijdragen, in het voorafgaande jaar, waar er op gewezen wordt ,,dat het zeer wenschelijk zou wezen, nog eene zorgvuldig gecollationneerde copie.... in Arabisch schrift te laten maken, en, zoo mogelijk, de mondelinge toelichtingen, die Pangéran Sjarif Sokmawira kan geven, te boek te stellen".

Bij de Geschiedenis van Sambas, welke in het $1^{\circ}$ deel van het Tijdschrift van het Bat. Gen. v. K. en W. (1853) vertaald en geannoteerd is door E. Netscher, staat de auteur even stil, en wel om dezen eigenaardigen vertaler, die destijds reputatie genoot, te caracteriseeren met enkele welverdiende woorden: „Netscher hat nicht nur manchmal sehr frei und fehlerhaft übersetzt, sondern auch den Text überall nach Belieben geändert, wo er ihm nicht deutltich oder fliessend genug erschien".

We zijn nu genaderd tot het hoofdstuk: Gesetssammlungen OstIndischer Reiche. Het eerste is het wetboek van Kedah (niet door Schömann bezorgd) een unicum, van vrij ouden datum, waarnaar indertijd te vergeefs gezocht is. Over mogelijkheid van uitgave wordt gezegd: Für die Herstellung einer Ausgabe dieses wichtigen Textes wäre ein zweites Exemplar fast unentbehrlich; ein solches scheint bisher nicht aufgefunden zu sein". (Er is nog een HS. te Batavia, maar niet identisch met dit). Dan: Malaka, critisch met de Leidsche HSS. vergeleken. De laatste afdeeling is: Politik, didaktische Werke, Kalender, Wahrsagerei, u.s.w. Ik noem slechts „De Kroon der 
Koningen", van verwelkte faam, waaraan critiek met andere HSS. wordt vastgeknoopt, overigens een prachtig specimen, datum: Juni, 1848 .

Bij de beschrijving van een magischen kalender treft ons des auteurs vermelding van zijnen genialen vriend, Prof. G. A. Wilken (gest. in 1891), die hem met de verklaring van enkele ondergeschikte punten geholpen had. Het slot vormt een drietal politieke stukken (niet ex-Schoemann), door Overbeck, o.a. bl. 255 als volgt beschreven: (a) „Fragment of a letter of the Captain of Hitu. Mentions Hitu, Makassar, Button.... (b) Original treaty in Malay characters between the Jukelan of Ternate, Raja Besar deri Molucci, and the Governor-General of the Dutch East Indies, dated Batavia 30th January 1650. A treaty on sovereigenty, and that all clove-trees in the king's state should be destroyed nd no new ones planted, against a payment of 6000 reals etc. Signed by Carel Reniersz. Joan Maetsuycker and other, and sealed with the seal of Sultan Manthar Shah".

(c) Original treaty in old Dutch and Malay, dated 18th June 1638, 10th March 1639 (gedaan Ternate, Casteel Malayen) between the Sultan of Ternate, and the Dutch East India Company, on commercial relations, political rights etc."

Het laatste nummer is (wèl ex Schoemann) een „,notizbuch”, en niets anders dan een particulier aanteekenboekje, welks menschelijk, maar niet zeer waardig of verheffend, besluit wordt gevormd door een ,schlechtes mit Javanismen gespicktes erotisches Gedicht, welches im Festenmonat geschrieben worden ist".

Hiermede eindigt de uitvoerige, beschrijvende catalogus.

Het zoude mijns inziens de moeite waard zijn dezen catalogus te doen uitgeven, en daardoor de serie der werken van den grooten oriïntalist te completeeren. Wel is waar biedt de beschrijving, wegens het verschijnen van uitvoerige catalogi, voornamelijk van de collecties te Leiden en Batavia in 1899 en 1909 niet in alle onderdeelen iets nieuws, maar als den schrijver typeerende „Jugendarbeit" mag dit opus, naar het ons voorkomt, niet verkort worden; hoogstens zouden in noten onder aan de bladzijden, waar de bespreking der HSS. eindigt, de in andere collecties Maleische handschriften voorkomende specimina kunnen worden aangeduid. Doch dit is posterioris curae; het voornaamste is dat deze catalogus, na verkregen machtiging, wordt gepubliceerd, eene taak waartoe de drie wetenschappelijke vereenigingen, die den schrijver tot lid, voorzitter en eere-lid mochten hebben, naar te veronderstellen valt, wel zullen willen medewerken. 
Zooals gezegd, mag o.i. het werk niet beknot worden, het was destijds gereed voor den druk. Dit geldt niet van de eerste bewerking dezer beschrijving, die eveneens onder de papieren van Snouck Hurgronje is aangetroffen, en waaraan wij ons veroorloven nog eenige woorden te wijden. $\mathrm{Ze}$ is niet in het Duitsch, maar in het Nederlandsch gesteld, overtreft in uitvoerigheid der beschrijving en der inhoudsopgaven het boven geschetste stuk, dat er blijkbaar uit geextraheerd is, in hooge mate. Elk onderdeel bevat een veelvoud van het aantal bladzijden dat er in het stuk zelf aan besteed is; eene vergelijking bv. van het getal pagina's ingenomen door de tekstcritiek op de uitgave van de Kroniek van Koetai in deel 37 onzer Bijdragen, in het Duitsche stuk en in het Hollandsche concept, zoude eene opklimmende reeks van merkwaardige verhouding der componenten geven. Zulk een opus uit te geven zoude niet verantwoord zijn; buitendien is het, zooals het daar ligt, niet persklaar.

Onze verbijstering bij het zien van den omvang der in zóó korten tijd voltooide boven besproken beschrijving wordt dus nog vergroot door de ontdekking dat ze een omwerking was van een nog veel breeder catalogus, welke op zich zelf zeer tijdroovend is geweest, te meer daar de auteur wegens op handen zijnd vertrek naar Indië, daaraan, te midden van zijne andere publicaties, niet ongestoord kon arbeiden.

Voor de geschiedenis van het geleerdenleven van C. Snouck Hurgronje is de vondst van stuk en ,vorarbeit” een merkwaardig gegeven. Toen zijne benoeming tot hoogleeraar in het Maleisch plaats vond (in 1891, op zijn verzoek ingetrokken in 1892), wekte dit bij sommigen verbazing; immers de toen ruim dertigjarige orientalist was arabicus en islamoloog van reeds toen gevestigde reputatite, van zijne kennis van het Maleisch had hij slechts door ééne studie, boven bedoeld, doen blijken, en hij was nog maar eenige maanden in Indië; wèl was bekend, dat hij tijdens zijn verblijf te Mekka, veel omgang met Sumatranen en Javanen gehad had, waarbij hij zich van modern Maleisch moet bediend hebben, doch dit bleek niet uit publicaties.

$\mathrm{Nu}$ zijne catalogiseering, met haar rijken inhoud, en de aan haar ten grondslag liggende volkomene bekendheid met de Maleische taal en litteratuur, aan het licht gekomen is, verkrijgen wij de overtuiging, dat de vermelde benoeming in het Maleisch de allerbeste was, die, zoo zij tot ambtsaanvaarding had geleid, aan het vak en de studie in de hoogste mate zou zijn ten goede gekomen.

Maar Snouck Hurgronje meende ze te moeten van de hand wijzen, 
evenals die te Berlijn, aan het Seminar für Orientalische Sprachen, en te Cambridge, aan de Universiteit. Zoo werd hij voor Indië behouden, vanwaar hij na een verblijf van zeventien jaren in Maart 1906 terugging, om den 30en Januari 1907 zijn hoogleeraarambt te Leiden te aanvaarden, dat hij tot zijne pensionneering in 1937, en in anderen vorm, tot zijn overlijden, op 26 Juni 1936, zoude blijven uitoefenen. 